\title{
New Approach to Identifying Critical Initial Conditions for Extreme Flood Simulations in a Semicontinuous Simulation Framework
}

\author{
Fränz Zeimetz, Ph.D. ${ }^{1}$; Bettina Schaefli ${ }^{2}$; Guillaume Artigue, Ph.D. ${ }^{3}$; \\ Javier García Hernández, Ph.D. ${ }^{4}$; and Anton J. Schleiss ${ }^{5}$
}

\begin{abstract}
Extreme flood simulation with synthetic extreme precipitation events raises unavoidable questions about the choice of initial conditions. State-of-the-art extreme flood estimation frameworks propose to address these questions with the help of semicontinuous modeling and reanalysis of simulated state variables. In this context, the present work proposes a new method for the selection of initial conditions for extreme flood simulation. The method is based on generating sets of initial conditions from the matrix of state variables corresponding to a long simulation run of the selected hydrological model. Two sets of initial conditions are obtained: a deterministic set composed of selected state variable quantiles and a stochastic set composed of state variable vectors randomly drawn from the complete state variable matrix. The extreme flood simulations corresponding to both sets are compared in detail, and the stochastic simulations are used in a sensitivity analysis to identify the dominant state variables and possible interactions. The aim hereby is to provide a tool to analyze the role of initial conditions and the importance to account for state variable interactions in extreme flood estimation. The proposed method is applied to probable maximum flood estimation for the Swiss Mattmark Dam catchment with a semilumped hydrological model. The obtained results for this case study show that for high flood peak quantiles, the initial soil saturation is dominating other state variables, and deterministic initial conditions are sufficient to generate extreme floods. DOI: 10.1061/(ASCE)HE.1943-5584.0001652. @ 2018 American Society of Civil Engineers.
\end{abstract}

Author keywords: Extreme floods; Hydrological simulation; Rainfall-runoff model; Initial conditions; Sensitivity analysis; Semicontinuous simulations; Snow; Glacier.

\section{Introduction and Objectives}

Engineers are frequently facing the difficult task of extreme flood estimations. In dam construction, for instance, a widely used concept for safety flood estimations is the probable maximum precipitation-probable maximum flood (PMP-PMF) approach (Swain et al. 2006; Nathan et al. 2001; Beauchamp et al. 2013; Casas et al. 2011; Jothityangkoon et al. 2013; Lagos-Zúniga and

${ }^{1}$ Researcher, School of Architecture, Civil Engineering, and Environmental Engineering, Laboratory of Hydraulic Constructions, Ecole Polytechnique Fédérale de Lausanne, Station 18, CH-1015 Lausanne, Switzerland; presently, Stucky Ltd., Avenue du Lac, 33, CH-1020 Renens, Switzerland (corresponding author). ORCID: https://orcid.org/0000-0002-9773-6238. Email: franz.zeimetz@epfl.ch

${ }^{2}$ Full Professor, Faculty of Geosciences and Environment, Institute of Earth Surface Dynamics, Université de Lausanne, CH-1015 Lausanne, Switzerland.

${ }^{3}$ Researcher, School of Architecture, Civil Engineering, and Environmental Engineering, Laboratory of Hydraulic Constructions, Ecole Polytechnique Fédérale de Lausanne, Station 18, CH-1015 Lausanne, Switzerland.

${ }^{4}$ Director of CREALP, Centre de recherche sur l'environnement alpin, Rue de l'Industrie 45, CH-1950 Sion, Switzerland.

${ }^{5}$ Full Professor, School of Architecture, Civil Engineering, and Environmental Engineering, Laboratory of Hydraulic Constructions, Ecole Polytechnique Fédérale de Lausanne, Station 18, CH-1015 Lausanne, Switzerland.

Note. This manuscript was submitted on June 15, 2017; approved on November 14, 2017; published online on May 24, 2018. Discussion period open until October 24, 2018; separate discussions must be submitted for individual papers. This paper is part of the Journal of Hydrologic Engineering, (C) ASCE, ISSN 1084-0699.
Vargas 2014; Salas et al. 2014; Haddad and Rahman 2016; Brigode et al. 2015; Zeimetz et al. 2015; Zeimetz 2017). The PMP is, according to the World Meteorological Organization (WMO 2009), the "... theoretical maximum precipitation for a given duration under modern meteorological conditions ...." The PMF is defined as "... the theoretical maximum flood that poses extremely serious threats to the flood control of a given project in a design watershed. [It is] converted from the probable maximum precipitation (PMP) over a design watershed." (WMO 2009).

If the conversion from a synthetic PMP hyetograph to a PMF hydrograph is undertaken with the help of hydrological simulations, the model has to be initialized before simulating the a single isolated PMP event. Here, the initialization of a hydrological model is understood as the process of attributing certain initial values to the state variables of the model.

Typical key state variables for simulations in Alpine catchments are the snow height and the soil saturation, which evolve during the simulations and depend on the model inputs as well as on the parameters of the model. The model output (discharge) at a certain moment directly depends on the state variables and on the meteorological model inputs. The initialization of the model becomes negligible after a certain simulation period (days to months, depending on the timescale of simulated state variable dynamics). This period is often called the model warm-up or spin-up. Because of the general strong seasonality of hydrologic phenomena, such a warm-up period will not result in some steady state but rather in time-varying initial conditions during baseflow conditions (before a rainfall event) during different seasons. Accordingly, it is readily understood that the choice of the initial conditions considered for a 
hydrological simulation can have a high impact on the simulated discharge (Hingray et al. 2009; Chen et al. 2016).

In this context, a semicontinuous simulation approach has been proposed by Beauchamp et al. (2013) to address the choice of appropriate model initial conditions. It consists in using a continuous hydrological model to simulate a state variable time series based on observed meteorological input data and deducing reasonable initial values from these long-term simulations for event-based flood simulations. This initialized continuous model is then used for the simulation of an isolated precipitation event.

Building on the preceding idea of state variable initialization with semicontinuous modeling, the objective of this paper is to present a new method for the selection of initial conditions. The overall goal is to determine whether one or a few state variables dominate the simulated peak flow or whether extreme flood estimation must account for complex interactions between the initial conditions for many state variables. The key hereby is a sensitivity analysis to quantify the influence of each state variable of a semilumped hydrological model with the possibility to account for interactions between the variables. This approach stems from the field of design of experiments and has been described by Box et al. (1978); however, it has not yet found much usage in hydrology despite the possibilities that it offers, as shown in this paper.

The proposed methodology is applied to a case study in the Swiss Alps, PMP-PMF estimation for the Mattmark Dam catchment. Despite linking the analysis to a case study, the applied methodology is readily transposable to every catchment and continuous hydrological modeling.

\section{Methodology}

In the context of semicontinuous modeling (Beauchamp et al. 2013), the number of simulations can be greatly reduced if the number of relevant state variables can be trimmed down to a minimum number. The basic idea is that a state variable can be neglected if a given range of corresponding initial conditions does not influence the quantiles of the simulated discharge, i.e., if the information contained in the quantiles of the initial conditions is lost. Such a loss could occur because of an eventual important dependence between the different state variables.

To investigate which state variables should be retained, the present methodological framework proposes to analyze a set of stochastic and deterministic initial conditions and to analyze their influence on the variation interval of the model outcome using the sensitivity analysis proposed by Box et al. (1978). Such an analysis keeps the number of simulations low while still guaranteeing an efficient sensitivity analysis through assessing the influence of all variables at the same time.

Through a complete understanding of the importance of the different state variables in the model, an informed selection of state variables and their values can be made, leading to a more efficient extreme flood simulation approach. The goal of studying stochastic and deterministic initial conditions in parallel is to analyze the influence of the initial conditions on the PMF estimate and to compare the results of the stochastic and deterministic approaches, with the aim of deciding whether the much faster deterministic approach is sufficient.

\section{Stochastic and Deterministic Initial Conditions}

Both the stochastic and the deterministic initial conditions are obtained from state variable values simulated during the longest possible period, corresponding to the entire period of available meteorological data. The simulated state variables for each spatial unit of the model are then weighted by the area of the modeling unit to obtain a catchment-scale averaged state variable value; this weighting arises because the hydrological state variables are typically expressed in terms of specific storage rather than in terms of volume.

If required, the simulated set of weighted state variables is divided into seasonal sets to focus the initial condition analysis only on seasons for which extreme flow events can actually occur. The stochastic approach is then based on a random selection of a moment in time at which the simulated state variables are selected as initial conditions for the extreme flow simulation.

For the present analysis, a set of 5,000 initial condition sets is generated from the summer season (the details are described subsequently). Once both sets of initial conditions are determined, the sensitivity of extreme flows with respect to these initial conditions is assessed by selecting a relevant extreme precipitation event (e.g., a PMP event) and by simulating the corresponding model response for each initialization. After the performance of these simulations, a quantile analysis is undertaken on the simulated flood hydrograph ensemble to understand how the distribution of extreme flows depends on the initial conditions. The resulting distribution merely describes the sensitivity of the simulated flows with respect to initial conditions, but that it does not allow estimating return periods.

For the deterministic approach, we decided to choose a quantile for each state variable and the corresponding state value. The chosen quantile is the same for each state variable. The number of required simulations corresponds to the chosen number of state variable quantiles. The extreme flow simulations are then performed by fixing the initial conditions to the corresponding quantile values within the season of interest. For this study, the $0.25,0.5$, and 0.95 quantiles are retained.

\section{Sensitivity Analysis: Determination of the Effect of Each State Variable}

A sensitivity analysis of the state variables on the maximum discharge is undertaken according to a method proposed by Box et al. (1978, Chapter 10), called Factorial designs at two levels, which is a method to design experiments to determine the effects of variables. This is an important step to understand the findings attributable to the comparison of the results from the stochastic and deterministic approaches. Furthermore, this step underlines the strength and the usefulness of the sensitivity analysis proposed by Box et al. (1978) to objectively choose between the two approaches for the determination of the initial conditions for semicontinuous extreme flood simulations. This analysis allows the most important state variables for the initialization of extreme flood simulations to be identified. Knowing the predominant state variables also leads to better comprehension of the simulation results and allows a more detailed analysis of the latter.

The key step of a two-level factorial design analysis following Box et al. (1978) is the choice of a maximum and a minimum value for each analyzed variable. Consequently, for $N$ variables, the number of possible combinations is $2^{N}$. In the context of this study, this means that with eight state variables (see "Glacier and SnowmeltSoil Contribution Hydrological Model"), $2^{8}=256$ simulations are performed to determine the main state variables [main effects in the vocabulary of Box et al. (1978)] for the simulation of peak discharges.

The sensitivity analysis is performed distinguishing between three different quantile ranges. This is necessary to discretize the analysis and to overcome the limitation of the two-level approach accounting only for two values per variable. This discretization 
leads indirectly to an analysis with more than two levels. This makes it possible to analyze whether the peak discharge sensitivity is changing within a certain range of values. The quantiles that are considered here as minimum and maximum values for the two-level design are $\{0.05,0.25\},\{0.40,0.60\}$, and $\{0.75,0.95\}$, derived from the summer initial conditions (the season relevant for PMP events). Hence, the number of simulations increases to $3 \cdot 2^{8}=768$.

Once the $2^{N}$ (here, $2^{8}=256$ ) simulations are performed for each of the three quantile ranges, the influence of the different variables on peak discharge simulation can be determined. The effects of the different considered state variables are estimated, according to Box et al. (1978) as follows:

$$
E_{j}=\frac{A_{j}^{\top} R}{N \sum_{i=1}^{N} R_{i}}
$$

where $A^{\top}=$ transposition of the design matrix with size $2^{N} \times\left[N+\left(N^{2}-N\right) / 2\right]$ containing 1 (to indicate the high level value) and -1 (to indicate the low level value); $N=$ number of considered state variables; $j=$ index of the state variable; $R=$ column vector containing the model outputs per simulation run and has thus the dimensions $2^{N} \times 1$; and $i=$ index of the simulation run.

The approach considered for this analysis also accounts for twofactor interactions. This means that, for example, the combined effect of the soil saturation and the snow height can be analyzed. The presence of the two-factor interactions in this analysis explains the number of columns of the design matrix. The columns corresponding to the interactions are derived by multiplying the columns of the design matrix (containing 1 and -1) corresponding to the state variables for which the interactions are considered to be interesting. In this study, all two-factor interactions are considered. This leads to $\left(N^{2}-N\right) / 2$ supplementary columns in the design matrix. The generated matrix (with dimensions $256 \times 36$ ) is too

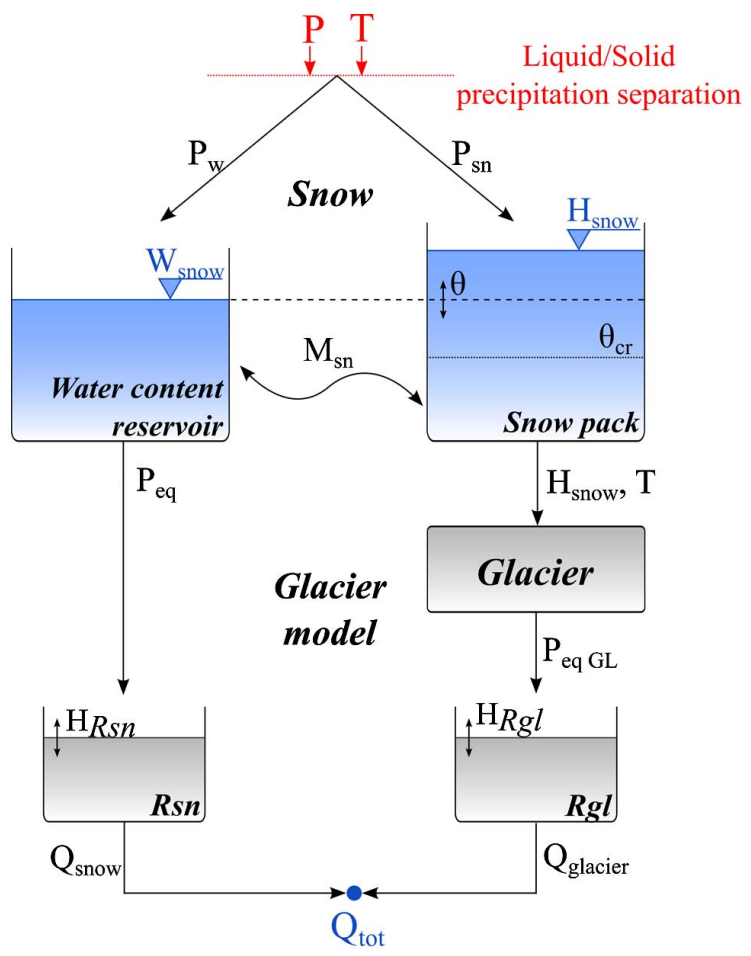

Fig. 1. Flowchart of the GSM model. (Reprinted from Garcìa Hernàndez et al. 2016, with permission.) large to be represented in this paper. The construction is described in detail in the work of Box et al. (1978).

\section{Glacier and Snowmelt-Soil Contribution Hydrological Model}

For the present study, the glacier and snowmelt-soil contribution (GSM-SOCONT) hydrological model is used. GSM-SOCONT is a semilumped hydrological model composed of the nonglacial SOCONT model and the extension to simulation of the GSM model. Both models are briefly exposed here. A detailed description and the underlying equations are presented by Schaefli et al. (2005), Schaefli and Huss (2011), and Jordan et al. (2012) and are summarized in the work of Garcìa Hernàndez et al. (2016), including a comprehensive flowchart. When using the GSM-SOCONT model, the subdivision of the catchment into elevation bands must be carried by distinguishing glacier and nonglacier areas. The GSM model is then used for the glacier elevation bands and the SOCONT model for the nonglacier bands. Fig. 1 shows a flowchart of the GSM model; the flowchart of the SOCONT model is presented in Fig. 2.

\section{GSM Model}

The inputs to the GSM model are precipitation and temperature time series. The GSM model is composed of a snow model and a glacier model. The snow model accounts for solid and liquid precipitation. The transition from liquid to solid is linear and depends on the temperature and commonly happens for temperatures between 0 and $2^{\circ} \mathrm{C}$. Observed snow and rainfall observations analyzed by Rohrer et al. (1994) confirm this hypothesis. A degreeday approach has been used to compute snowmelt (Hock 2003). If the critical saturation threshold of $\theta_{c r}=0.1$ is reached, meltwater leaves the snow pack. The water contained in the snow pack can refreeze in negative temperatures. The outflow from the snow

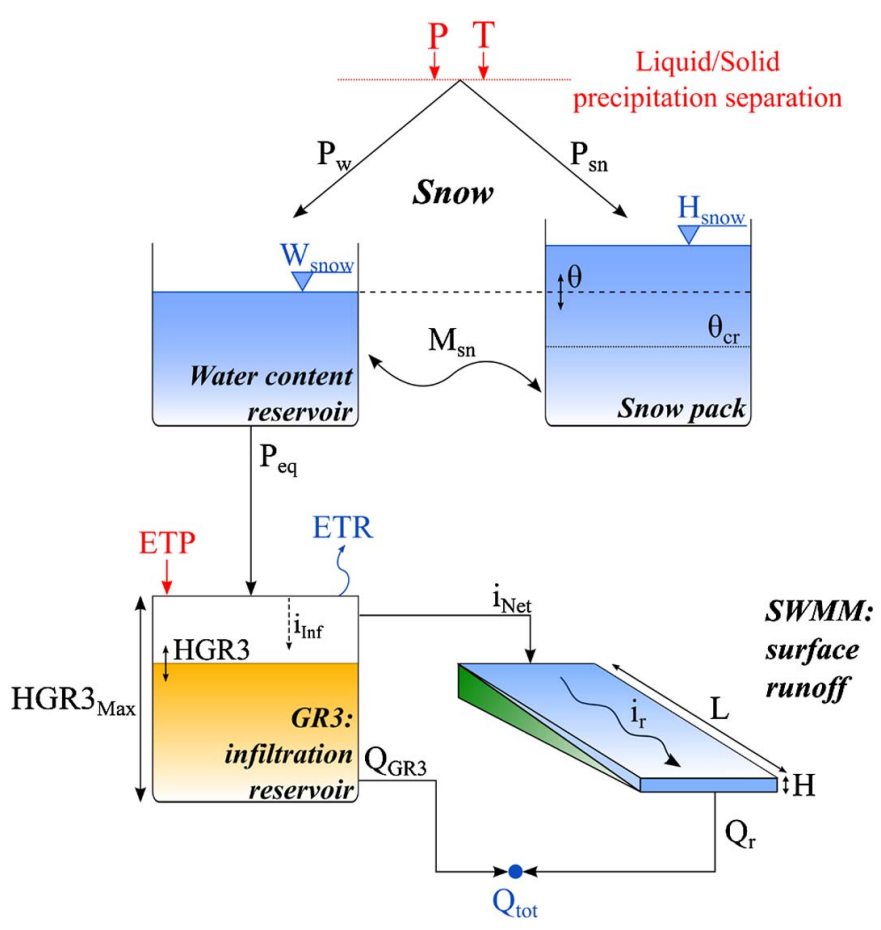

Fig. 2. Flowchart of the SOCONT model. (Reprinted from Garcìa Hernàndez et al. 2016, with permission.) 
pack $\left(Q_{s}\right)$ is simulated with two linear reservoirs: a fast reservoir (part of the snow model), and a slow reservoir (part of the glacier model). If the snow height is zero, the ice melt process starts. The glacier outflow is simulated through a single linear reservoir. The melt process is also simulated with a degree-day approach. The total discharge $\left(Q_{\mathrm{tot}}\right)$ generated by the glacier model corresponds to the sum of the snow $\left(Q_{s}\right)$ and glacier melt $\left(Q_{g l}\right)$ discharges. The state variables of the GSM model are the snow height, the snow saturation, the glacier melt, and the snowmelt discharges.

\section{SOCONT Model}

The inputs to the SOCONT model are precipitation, temperature, and potential evapotranspiration time series. The SOCONT model has the same snow model as the GSM model. The water leaving the snow model (snowmelt and liquid precipitation) is supposed to partially infiltrate into the subsoil. One portion of the outflow from the snow model is lost by evapotranspiration. The degree of infiltration depends on the saturation of the subsoil. A linear reservoir is used to simulate the outflow of the infiltrated water $\left(Q_{G R 3}\right)$. The portion of the water coming from snowmelt that does not infiltrate into the subsoil $\left(i_{\mathrm{Net}}\right)$ is routed as surface runoff with the Storm Water Management Model (SWMM). The total discharge $\left(Q_{t o t}\right)$ generated by the SOCONT model corresponds to the sum of the discharge leaving the soil model $\left(Q_{G R 3}\right)$ and the surface runoff $\left(Q_{r}\right)$. The state variables of the SOCONT model are the snow height, the snow saturation, the soil saturation, and the runoff height.

\section{Case Study of the Mattmark Dam Catchment}

To illustrate the application of the proposed method for the analysis of initial conditions for extreme flow simulation, the selected case study is PMP-PMF simulation for the Mattmark Dam, situated in the southern Swiss Alps (Fig. 3), for which the lake inflow and lake levels are simulated with the GSM-SOCONT model. Around 28\% $\left(10 \mathrm{~km}^{2}\right)$ of the entire catchment area $\left(36 \mathrm{~km}^{2}\right)$ is covered by glaciers. The basin goes from 2,197 $\mathrm{m}$ above sea level (ASL) to 3,920 m ASL. Because of the small size of the study catchment, the hydrological model used for this study does not take into account river routing. The water captured by seven lateral intakes (Fig. 3) is adducted through a collector to the reservoir. The collector has a capacity of $16 \mathrm{~m}^{3} / \mathrm{s}$.

For this case study, PMP data was extracted from the Swiss PMP maps (Hertig et al. 2005; Hertig and Fallot 2009). These maps had been developed during a 15-year research project with a meteorological model considering temperature, wind speed, and topography. The validity of the generated PMP maps was assessed through a comparison of the PMP values at different locations with extrapolated observed precipitation data by calculating the ratio between the 500-year precipitation and the PMP data at the location of the meteorological station (Hertig and Fallot 2009). For the PMP-PMF simulations, a 3-h PMP was chosen for illustration purposes. The mean intensity of this precipitation event was $94 \mathrm{~mm} / \mathrm{h}$ for the examined region.

The determination of the stochastic and deterministic initial conditions for the PMP-PMF simulations was based on the matrix of state variable time series simulated with an hourly time step for a period of 14 years (1980-1994). A set of 15 meteorological stations with hourly data provided by MeteoSwiss (n.d.) was used as model input. The available data period, although relatively short, covers a wide range of hydrological conditions, with very snow-rich winters in the early 1980s and snow-poor winters in the early 1990s. All dominant hydrological processes encoded in the model are triggered numerous times every year.

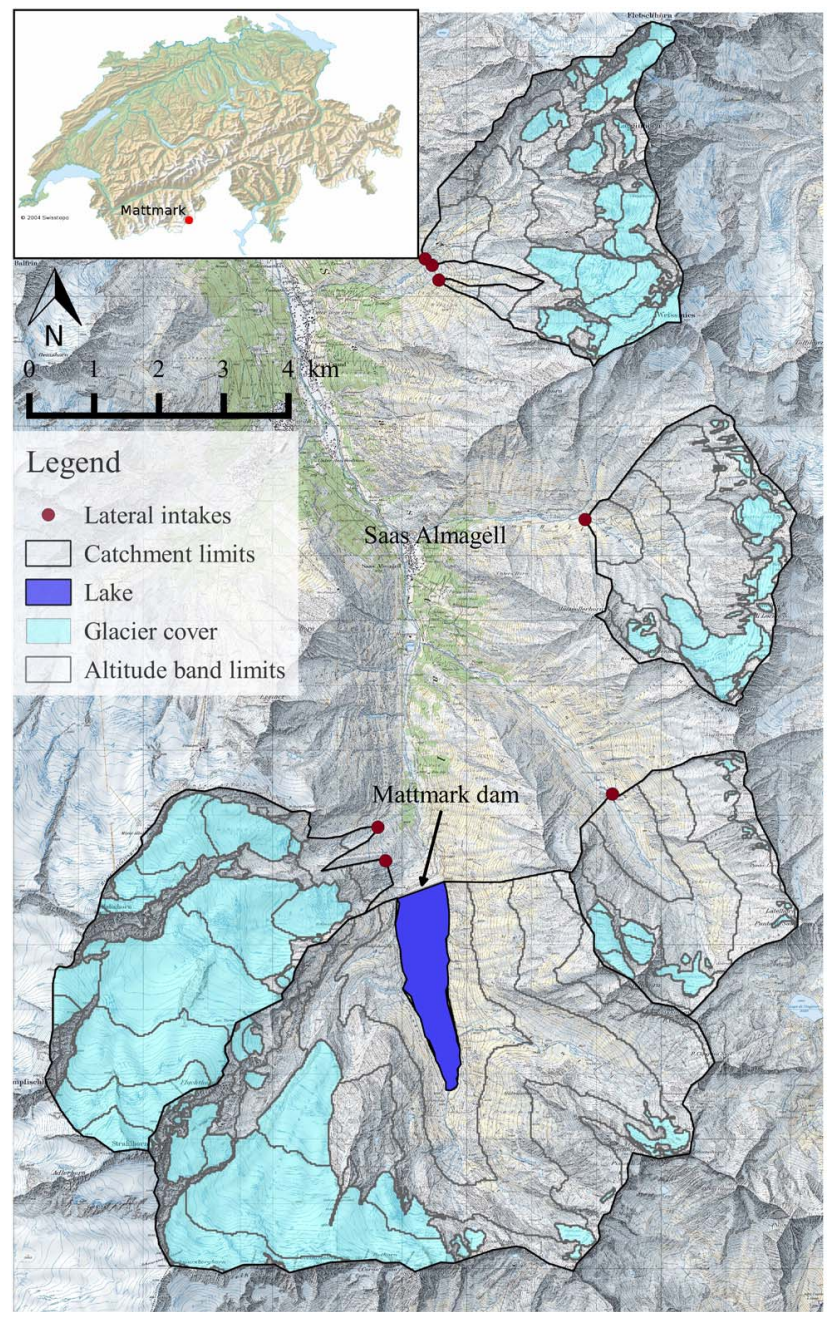

Fig. 3. Catchment of the Mattmark Dam with indication of the subdivision into elevation bands and situation of the dam on a map of Switzerland. (Reprinted from Zeimetz 2017.)

Because the PMP maps are valid for the summer season (June to August) only, the initial conditions were derived from the simulations corresponding to the three summer months. For the stochastic initial conditions, the sample of 5,000 randomly chosen time steps (from a period of 14 summers) corresponds, on average, to a selected time step every $6 \mathrm{~h}$.

The height of the $0^{\circ} \mathrm{C}$ isothermal altitude has been fixed at $H=$ 4,780 $\mathrm{m}$ ASL, according to the maximum observed isothermal altitude before a 3-h rainfall event in the southern part of the Alps (Zeimetz et al. 2017). The temperature conditions are thus high enough to avoid snowfall during the PMP event.

Because the Mattmark catchment is modeled with the semilumped GSM-SOCONT hydrological model, a subdivision in elevation bands has to be performed. An elevation interval of $300 \mathrm{~m}$ is used here for these bands. The determination of the elevation bands is based on a digital elevation model with a horizontal resolution of $25 \mathrm{~m}$ [modèle numérique de terrain horizontal resolution of 25m (MNT25) published in 2004 by Swisstopo (Federal Office of Topography 2004)]. The catchment and the subdivision in elevation bands are shown in Fig. 3.

The state variable values used for the present study are extracted from hourly GSM-SOCONT simulations from October 1995 to November 2009 on the Mattmark Dam catchment. The eight state variables are snow height, snow saturation, soil saturation, and runoff height (depth of the surface runoff model) for the nonglacier 
Table 1. Performance coefficients for the calibration and validation periods of the hydrological model

\begin{tabular}{lccc}
\hline Period & Nash-Sutcliffe & Kling-Gupta & Volume ratio \\
\hline Calibration & 0.89 & 0.94 & 0.99 \\
Validation & 0.90 & 0.86 & 0.91 \\
\hline
\end{tabular}

elevation bands, and snow height, snow saturation, glacier discharge, and snowmelt for the glacier elevation bands.

\section{Calibration and Validation of the Hydrological Model}

For the calibration and validation of the model, the meteorological data set has been divided into two sets of 7 years of precipitation and temperature data, and the first half was used for calibration (19952001) and the second half for validation (2002-2009). The rainfallrunoff model was calibrated automatically with the shuffled complex evolution algorithm developed at The University of Arizona (SCEUA) algorithm (Duan et al. 1993, 1994) using the Nash-Sutcliffe (NS) (Nash and Sutcliffe 1970) and the Kling-Gupta (KG) (Gupta et al. 2009) efficiency as well as the volume ratio (V) (simulated volume/observed volume) combined in a single objective function $F=N S+2 \cdot K G-(V-1)$, which has to be maximized [further details on the model calibration are available in the work of Zeimetz (2017)]. The performance during the validation period was also assessed with the KG (Gupta et al. 2009) efficiency and with the volume ratio (simulated volume/observed volume). For the calibration and the validation periods, the model gave good results (Table 1).

\section{Results and Discussion}

\section{Generated State Variable Values and Determined Initial Conditions Used for the Flood Simulations}

Hereafter, the values for the initial conditions, on which the PMF estimates have been based, are explained and represented for the four seasons of the year for exhaustivity reasons. However, for the initialization of the PMP-PMF simulation, it was assumed that the PMF could only occur during summer (Hertig and Fallot 2009).

\section{Stochastic Approach}

Because it is not possible to represent the 5,000 generated initial conditions sets, the representation of the evolution of the state variables during the 14 years of simulation is used to illustrate the state variable time series on which the initial condition generator is based. The state variable evolutions are shown in Fig. 4, which shows the variation quantiles derived from the ensemble of the mean simulated state variable values. The mean value was obtained by weighting the values of each elevation band by the area of the latter ("Stochastic and Deterministic Initial Conditions").

\section{Deterministic Approach}

For the deterministic approach, the values of the state variables retained as initial conditions for the PMP-PMF simulations are derived from the empirical cumulative density functions shown on Fig. 5. As for the stochastic approach, they are derived from the 14 years of simulated data. Table 2 reports the values for the 25,50 , and $95 \%$ quantiles for summer. The initial state variable values retained for the sensitivity analysis are provided in Table 3.

\section{Flood Simulation Results}

To compare the results of the two approaches (stochastic and deterministic), the 25,50 , and $95 \%$ quantiles have been derived from the discharge ensemble simulations and represented together with the prediction intervals for the 5,000 stochastically generated scenarios. These quantile hydrographs were then compared with the simulation results of the deterministic approach. For the comparison, the results of the two approaches were superposed (Fig. 6). The gray shaded distribution represents the variation of the discharges at each time step owing to the different initial conditions $(5,000$ scenarios).

The results indicate a high sensitivity of the hydrograph to the initial conditions. The pronounced sensitivity confirms the
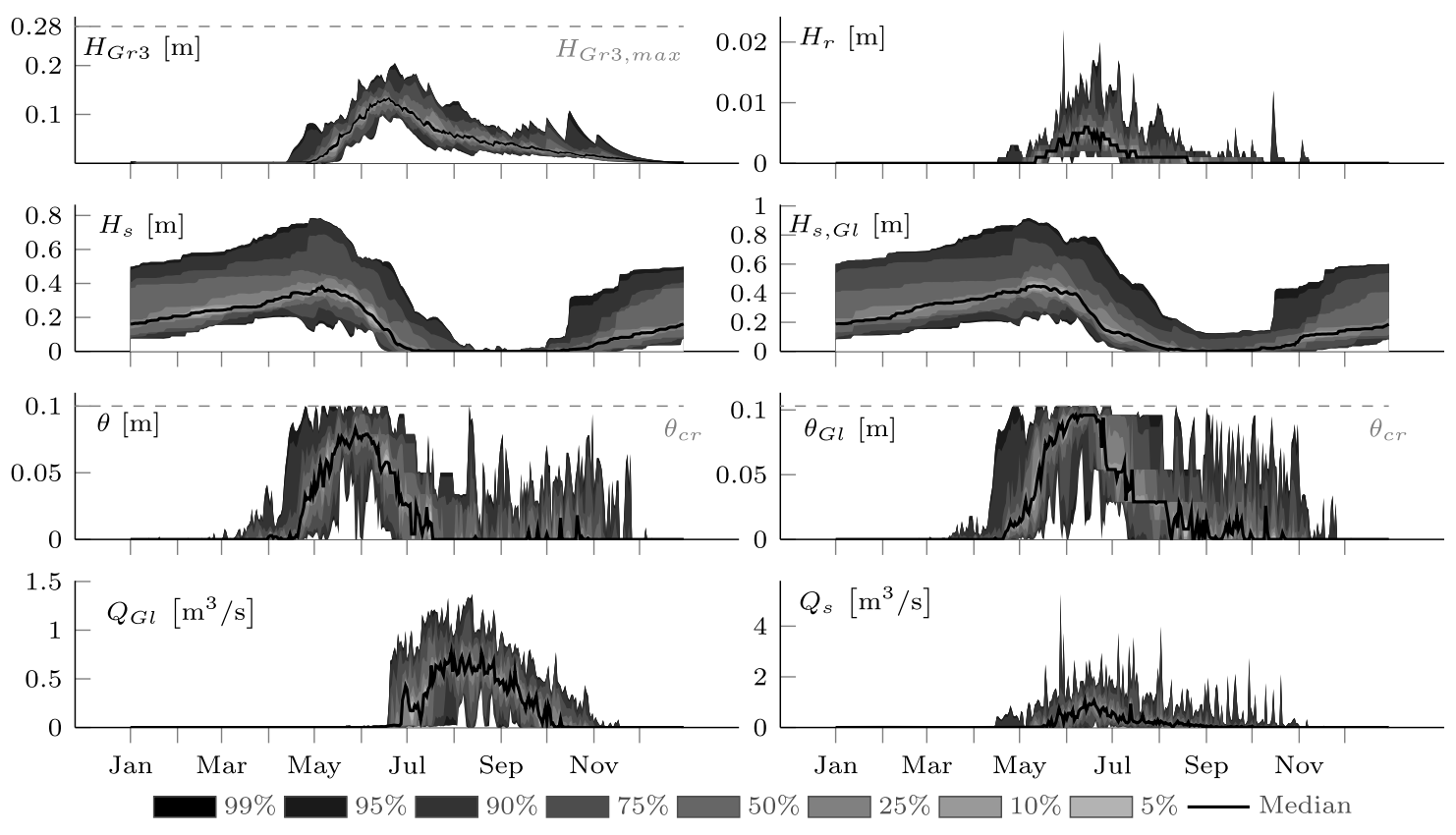

Fig. 4. Evolution over time with variation interval of the eight state variables of the GSM-SOCONT model, i.e., soil saturation $H_{G R 3}$, runoff height $H_{r}$, snow height $H_{s}$, snow height on glacier $H_{s, g l}$, snow saturation $\theta$, snow on glacier saturation $\theta_{g l}$, glacier melt $Q_{g l}$, snowmelt on glacier $Q_{s}$. (Reprinted from Zeimetz 2017.) 


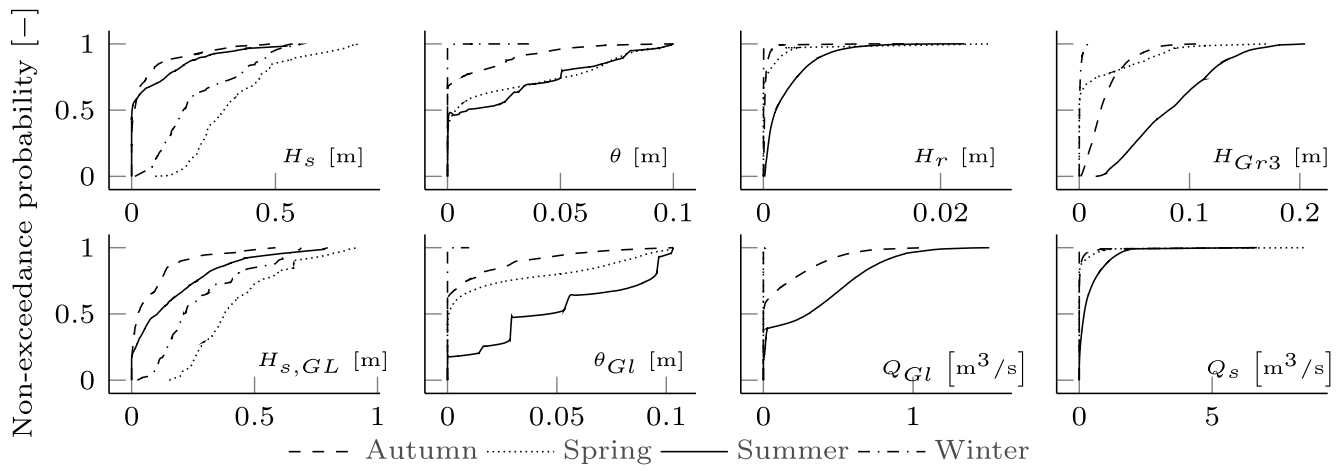

Fig. 5. Seasonal cumulative density functions of the state variables of the GSM-SOCONT model, i.e., soil saturation $H_{G R 3}$, runoff height $H_{r}$, snow height $H_{s}$, snow height on glacier $H_{s, g l}$, snow saturation $\theta$, snow on glacier saturation $\theta_{g l}$, glacier melt $Q_{g l}$, snowmelt on glacier $Q_{s}$. (Reprinted from Zeimetz 2017.)

Table 2. Summer state variable values for the 25,50 , and $95 \%$ quantiles considered for the hydrological model initialization

\begin{tabular}{lcccccc}
\hline Region & State variable & Symbol & $25 \%$ & $50 \%$ & $95 \%$ & Unit \\
\hline Nonglacial & Snow height & $H_{s}$ & 0 & 0.002 & 0.364 & $\mathrm{~m}$ \\
& Snow saturation & $\theta$ & 0 & 0.009 & 0.083 & $\mathrm{~m}$ \\
& Runoff height & $H_{r}$ & 0.0006 & 0.0014 & 0.008 & $\mathrm{~m}$ \\
& Soil saturation & $H_{G R 3}$ & 0.050 & 0.081 & 0.154 & $\mathrm{~m}$ \\
Glacial & Snow height & $H_{s, g l}$ & 0.018 & 0.104 & 0.570 & $\mathrm{~m}$ \\
& Snow saturation & $\theta_{g l}$ & 0.015 & 0.046 & 0.101 & $\mathrm{~m}$ \\
& Glacier melt & $Q_{g l}$ & 0.012 & 0.299 & 0.932 & $\mathrm{~m}^{3} / \mathrm{s}$ \\
& Snowmelt & $Q_{s}$ & 0.036 & 0.182 & 1.441 & $\mathrm{~m}^{3} / \mathrm{s}$ \\
\hline
\end{tabular}

importance of the choice of the initial conditions for extreme flood estimations.

It is interesting to notice that the deterministic approach gives result quantiles that, when compared to the quantiles derived from the stochastic approach, are nearly identical. This result can be explained through the sensitivity analysis, showing the influence of every initial state variable value on the peak discharges.

\section{Results and Discussion of the Sensitivity Analysis}

The estimated effects are plotted to visualize the effect for each variable (Fig. 7); the most significant interactions are plotted as well. Under the assumed summer conditions, the soil saturation is the most important state variable for low and high quantile values. The influence of snow height is also important when median values are chosen. However, the small snow height (Table 2) makes the absolute influence rather negligible in the case of Mattmark. Because the 75 and $95 \%$ quantile hydrographs are mainly influenced by a single state variable explains the good correspondence between the results of the deterministic and stochastic approaches. The estimates of the median hydrograph from the two approaches are less similar.

The sensitivity analysis indicates an important influence of two state variables, i.e., soil saturation and snow height. The fact that these state variables interact leads to the differences between the stochastic and the deterministic approach (which neglects the dependence/interaction) that can be observed in Fig. 6 .

An interesting result is that the snow effects are negative for high quantile values. This means that the snow is actually attenuating the peak discharge. This results from the retention of a part of the precipitation in the initially unsaturated snow (Table 3) that remains after the precipitation event. It should be remembered here that the water holding capacity of the snow is reached for $\theta=0.1$

Notice that the effect analysis shows that the initial conditions of the glacier bands do not have much influence on the peak discharge. A reflection on the origin of the glacier discharge can clarify this issue. In fact, the glacier discharge is generated by a snow and glacier melt model. The initial conditions of the glacier melt model only concern its initial melt outflow. The melting of the glacier and the snow is modeled by a degree-day approach and depends only on temperature. The rainfall-runoff transformation of rainfall falling on the glacier is thus not influenced by the initial conditions of the glacier bands. Whereas in the case of nonglacier bands, rainfall-runoff transformation is influenced by the initial saturation of the soil. The soil has the ability to retain a part of the water and releases it slowly as baseflow, which leads to an attenuating of the discharge. The initial snow cover on the glacier and on the nonglacier bands can be seen as a water volume added to the water coming from rainfall. Under the assumption that the snow is

Table 3. Summer state variable values for the quantiles considered for the hydrological model initialization in the context of the sensitivity analysis

\begin{tabular}{|c|c|c|c|c|c|c|c|c|c|}
\hline \multirow[b]{2}{*}{ Region } & \multirow[b]{2}{*}{ State variable } & \multirow[b]{2}{*}{ Symbol } & \multicolumn{2}{|c|}{ Range 1} & \multicolumn{2}{|c|}{ Range 2} & \multicolumn{2}{|c|}{ Range 3} & \multirow[b]{2}{*}{ Unit } \\
\hline & & & $5 \%$ & $25 \%$ & $40 \%$ & $60 \%$ & $75 \%$ & $95 \%$ & \\
\hline \multirow[t]{4}{*}{ Nonglacial } & Snow height & $H_{s}$ & 0 & 0 & 0 & 0.022 & 0.120 & 0.360 & $\mathrm{~m}$ \\
\hline & Snow saturation & $\theta$ & 0 & 0 & 0 & 0.026 & 0.05 & 0.083 & $\mathrm{~m}$ \\
\hline & Runoff height & $H_{r}$ & 0.0002 & 0.0006 & 0.001 & 0.002 & 0.004 & 0.008 & $\mathrm{~m}$ \\
\hline & Soil saturation & $H_{G R 3}$ & 0.027 & 0.050 & 0.066 & 0.094 & 0.115 & 0.154 & $\mathrm{~m}$ \\
\hline \multirow[t]{4}{*}{ Glacial } & Snow height & $H_{s, g l}$ & 0 & 0.018 & 0.0 .056 & 0.16 & 0.260 & 0.570 & $\mathrm{~m}$ \\
\hline & Snow saturation & $\theta_{g l}$, & 0 & 0.015 & 0.029 & 0.054 & 0.091 & 0.100 & $\mathrm{~m}$ \\
\hline & Glacier melt & $Q_{g l}$ & 0 & 0.012 & 0.055 & 0.423 & 0.586 & 0.932 & $\mathrm{~m}^{3} / \mathrm{s}$ \\
\hline & Snowmelt & $Q_{s}$ & 0 & 0.036 & 0.115 & 0.279 & 0.559 & 1.440 & $\mathrm{~m}^{3} / \mathrm{s}$ \\
\hline
\end{tabular}




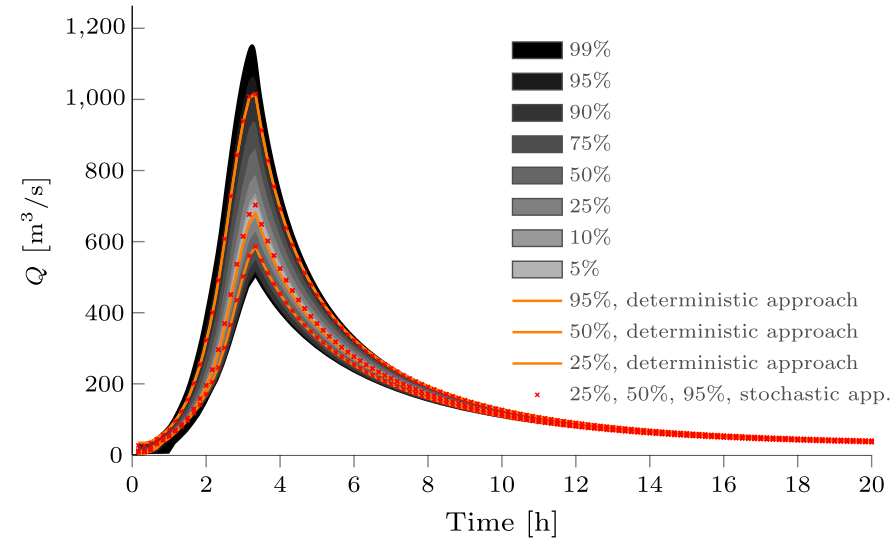

Fig. 6. Superposition of the hydrographs derived from the stochastic and deterministic approach as well as the prediction intervals (shaded in gray) derived from the stochastic approach. (Reprinted from Zeimetz 2017.)

saturated or completely melts during the precipitation event, it has no capacity of storing the precipitated water and thus of reducing the routed water amount.

The case of a nonsaturated snow has already been discussed. The sensitivity analysis shows that the reduction of the discharge due to the snow is rather small and occurs only if the initial snow cover is high. For these reasons, the influence on the peak discharge of nonglacier bands is higher than the influence of the glacier bands.

This case study did not allow to satisfactorily address the issue of the interactions. In catchments where the snow pack is remaining longer than is the case for this analysis, the interaction between the snow and the soil saturation cannot be neglected. In the present study, the snow cover was too small to generate significant interaction effects. If interactions have a non-negligible influence on the model output, the dependence between the variables should be considered. Thus, the deterministic approach would certainly not be a reliable approach for extreme flood estimation, because it cannot account for the variable dependence. The stochastic initial condition generator would be a better solution in that case. To determine which approach is best, a sensitivity analysis should be performed if the predominance of a single state variable cannot be assumed a priori.

\section{Conclusions}

This paper proposed a new method for the selection of initial conditions in the context of extreme flood estimation based on semicontinuous simulation. The method relies on two steps: (1) comparison of simulated extreme floods obtained from deterministic initial conditions and from stochastic initial conditions; and (2) a sensitivity analysis to understand differences between the deterministic and the stochastic simulations and to identify dominant state variables and their interactions. All initial conditions are obtained from an analysis of the state variables corresponding to a long run of the selected hydrological model. For the deterministic case, the set of initial conditions corresponds to selected quantiles $(0.25,0.5$, and 0.95$)$; for the stochastic case, the set of initial conditions is obtained by randomly sampling a high number of time steps of the available simulation and retaining the corresponding state variable values as initial conditions. Comparing the simulations from both sets of initial conditions sheds light on the interactions between state variables (which are neglected in the deterministic case). The ensuing sensitivity analysis on the set of stochastic simulations allows identifying dominant state variables and interactions and ultimately deciding which state variables to retain for extreme flood estimation.

The relevance of this work lies in this proposed framework to determine how to account for the initial conditions of several, potentially interacting, state variables. As illustrated for the Mattmark case study in Switzerland, the method helps identify the dominant state variables (in this case, soil saturation, followed by snow height) and possible interactions (negligible in the discussed example). Such a result is key in identifying the relevant state variables for extreme flood simulation, namely, to decide whether a few deterministic simulations can give good extreme flood estimations or whether a range of stochastic simulations is required to account for complex state variable interactions. In the case study, a single state variable (soil saturation) dominates the model response for high summer flows; accordingly, a probable maximum flood can be estimated by selecting an adverse initial condition (e.g., 90\% saturation) for this state variable.

Any flood estimation project based on hydrologic modeling needs to have a strong focus on the analysis and on the choice of case study-specific initial conditions. A well-designed sensitivity analysis, like the one proposed in this paper, can add precious information to this process. If the sensitivity analysis shows that the dominant state variables are interacting (i.e., that the simulated extreme flood does not linearly depend on each of them), a stochastic

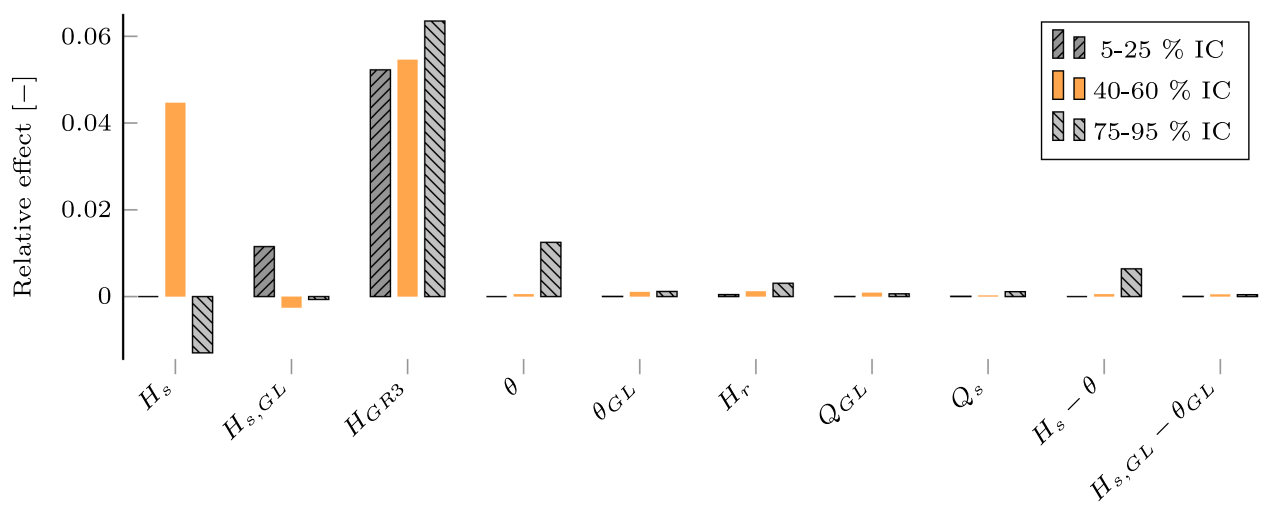

Fig. 7. Relative effects on the PMF peak discharge of the initial state variables of the GSM-SOCONT model, i.e., soil saturation $H_{G R 3}$, runoff height $H_{r}$, snow height $H_{s}$, snow height on glacier $H_{s, g l}$, snow saturation $\theta$, snow on glacier saturation $\theta_{g l}$, glacier melt $Q_{g l}$, snowmelt on glacier $Q_{s}$ as well as the effect of the interaction between the snow height and the saturation for glacial and nonglacial zones. (Reprinted from Zeimetz 2017.) 
approach should be preferred for extreme flood estimation. If, in exchange, the sensitivity analysis shows that one or a few state variables are dominant with negligible interactions, extreme flood simulation can safely rely on a small set of selected initial conditions. In either case, the detailed sensitivity analysis forms the basis of an informed and readily understood choice of the initial conditions, which is key for communicating, e.g., with agencies in charge of dam security. Furthermore, for a given model, the conclusions from such an initial condition analysis are transferable across catchments with the same dominant hydrological processes.

\section{Acknowledgments}

This work was funded by the Swiss Federal Office of Energy (SFOE). The work of Bettina Schaefli was supported by the Swiss Competence Center on Energy Research-Supply of Energy (http:// www.sccer-soe.ch) and by the Swiss National Science Foundation (SNSF), grant number PP00P2_157611. Measured precipitation data has been provided by MeteoSuisse. The authors thank the engineering companies Hydrique IngÉnieurs for the use of their hydrological modeling software as well as the engineering company Hertig \& Lador SA for the PMP data, they elaborated for the SFOE. The used hydrologic model is also freely available within the software package "Routing System Minerve" (https://www.crealp.ch /fr/accueil/outils-services/logiciels/rs-minerve/telechargement-rsm .html) with add-ins for flood analysis. The sensitivity analysis was completed with Matlab, but free software like R, using the R-packages AlgDesign, DoE.base, and FrF2, or Octave, using the fullfact function for the design matrix generation, could be used to accomplish the analysis. The helpful comments of three anonymous reviewers and of the managing editor greatly improved the quality of this manuscript.

\section{Notation}

The following symbols are used in this paper:

$A=$ design matrix;

$E=$ relative effect matrix;

$H_{G R 3}=$ soil saturation $(\mathrm{mm})$;

$H_{r}=$ runoff height $(\mathrm{mm})$;

$H_{s}=$ snowpack depth $(\mathrm{mm})$ (water equivalent);

$i=$ index of the simulation run;

$j=$ index of the state variable;

$N=$ number of considered state variables;

$Q_{g l}=$ glacier melt $\left(\mathrm{mm} d^{-1}\right)$;

$Q_{s}=$ snowmelt $\left(\mathrm{mm} d^{-1}\right)$;

$R=$ column vector containing the model outputs per simulation run;

$\top=$ operation of matrix transposition; and

$\theta=$ snow saturation.

\section{References}

Beauchamp, J., R. Leconte, M. Trudel, and F. Brissette. 2013. "Estimation of the summer-fall PMP and PMF of a northern watershed under a changed climate." Water Resour. Res. 49 (6): 3852-3862. https://doi .org/10.1002/wrcr.20336

Box, G., W. Hunter, and J. Hunter. 1978. Statistics for experimenters: An introduction to design, data analysis, and model building. New York: Wiley.

Brigode, P., Z. Micovic, P. Bernardara, E. Paquet, J. Gailhard, F. Garavaglia, R. Garçon, and P. Ribstein. 2015. "Probabilistic and deterministic extreme flood estimation methods: Estimation comparison on two British Columbia catchments (Canada)." Houille Blanche 2015 (3): 72-78. https://doi.org/10.1051/lhb/20150036.

Casas, M. C., R. Rodríguez, M. Prohom, A. Gázquez, and A. Redaño. 2011. "Estimation of the probable maximum precipitation in Barcelona (Spain)." Int. J. Climatol. 31 (9): 1322-1327. https://doi.org/10.1002 /joc.2149.

Chen, J., M. L. Kavvas, K. Ishida, T. Trinh, N. Ohara, M. L. Anderson, and Z. Q. R. Chen. 2016. "Role of snowmelt in determining whether the maximum precipitation always results in the maximum flood." $J$. Hydrol. Eng. 21 (10): 04016032. https://doi.org/10.1061/(ASCE)HE.1943 $-5584.0001366$.

Duan, Q., V. K. Gupta, and S. Sorooshian. 1993. "A shuffled complex evolution approach for effective and efficient global minimization." J. Optim. Theory Appl. 76 (3): 501-521. https://doi.org/10.1007 /BF00939380.

Duan, Q., S. Sorooshian, and V. K. Gupta. 1994. "Optimal use of SCE-UA global optimization method for calibrating watershed models." J. Hydrol. 158 (3-4): 265-284. https://doi.org/10.1016/0022-1694(94) 90057-4.

Federal Office of Topography. 2004. Switzerland's national mapping agency. Swisstopo MNT25. Wabern, Switzerland: Federal Office of Topography.

Garcìa Hernàndez, J., J. Paredes Arquiola, A. Foehn, and B. Roquier. 2016. RS Minerve-Technical manual v1.7. Sion, Switzerland: Centre de recherche sur l'environnement alpin.

Gupta, H. V., H. Kling, K. K. Yilmaz, and G. Martinez. 2009. "Decomposition of the mean squared error and NSE performance criteria: Implications for improving hydrological modelling." J. Hydrol. 377 (1-2): 80-91. https://doi.org/10.1016/j.jhydrol.2009.08.003.

Haddad, K., and A. Rahman. 2016. "Estimation of large to extreme floods using a regionalization model." Chap. 14, Part III, in Landscape dynamics, soils and hydrological processes in varied climates, edited by A. M. Melesse and W. Abtew. Cham, Switzerland: Springer.

Hertig, J.-A., A. Audouard, and A. Plancherel. 2005. Cartes des précipitation extrêmes pour la Suisse (PMP 2005). Rapport EFLUM-EPFL. [In French.] Lausanne, Switzerland: Ecole Polytechnique Fédérale de Lausane.

Hertig, J.-A., and J.-M. Fallot. 2009. Validation et utilisation des cartes de PMP pour l'obtention de la PMF. Projet CRUEX: Directives Crues de l'OFEN. [In French.] St. Livres, Switzerland: Hertig \& Lador SA.

Hingray, B., C. Picouet, and A. Musy. 2009. Hydrologie 2-Une science pour l'ingÉnieur. [In French.] Lausanne, Switzerland: Presses polytechniques et universitaires romandes.

Hock, R. 2003. "Temperature index melt modelling in mountain areas." J. Hydrol. 282 (1-4): 104-115. https://doi.org/10.1016/S0022-1694 (03)00257-9.

Jordan, F., T. Brauchli, J. Garcia Hernandez, M. Bieri, and J. L. Boillat. 2012. RS 2012, Rainfall-runoff modelling: User guide. Le Mont-surlausanne, Switzerland: Hydrique Ingénieurs.

Jothityangkoon, C., C. Hirunteeyakul, K. Boonrawd, and M. Sivapalan. 2013. "Assessing the impact of climate and land use changes on extreme floods in a large tropical catchment." J. Hydrol. 490 (May): 88-105. https://doi.org/10.1016/j.jhydrol.2013.03.036.

Lagos-Zúñiga, M. A., and M. X. Vargas. 2014. "PMP and PMF estimations in sparsely-gauged Andean basins and climate change projections." Hydrol. Sci. J. 59 (11): 2027-2042. https://doi.org/10.1080/02626667 2013.877588.

MeteoSwiss. n.d. Switzerland's national weather service. Bern, Switzerland: Federal Dept. of Home Affairs.

Nash, J. E., and J. V. Sutcliffe. 1970. "River flow forecasting through conceptual models Part I-A discussion of principles." J. Hydrol. 10 (3): 282-290. https://doi.org/10.1016/0022-1694(70)90255-6.

Nathan, R., P. Hill, and H. Griffith. 2001. "Risk implications of the PMF and the PMP design flood." In New Zealand Society on Large dams (NZSOLD)/Australian National Committee on Large Dams (ANCOLD) Conf. on Dams. Australia.

Rohrer, M. B., L. N. Braun, and H. Lang. 1994. "Long-term records of snow cover water equivalent in the Swiss Alps. 1. Analysis." Nordic Hydrol. 25 (1-2): 53-64. 
Salas, J. D., G. Gavilán, F. R. Salas, P. Y. Julien, and J. Abdullah. 2014. "Uncertainty of the PMP and PMF." In Handbook of engineering hydrology. Boca Raton, FL: Taylor \& Francis.

Schaefli, B., B. Hingray, M. Niggli, and A. Musy. 2005. "A conceptual glacio-hydrological model for high mountainous catchments." Hydrol. Earth Syst. Sci. 9 (1/2): 95-109. https://doi.org/10.5194/hess-9-95 -2005 .

Schaefli, B., and M. Huss. 2011. "Integrating point glacier mass balance observations into hydrologic model identification." Hydrol. Earth Syst. Sci. 15 (4): 1227-1241. https://doi.org/10.5194/hess-15-1227 $-2011$.

Swain, R., J. England, K. Bullard, and D. Raff. 2006. Guidelines for evaluating hydrologic hazards. Denver: US Dept. of the Interior, Bureau of Reclamation.
WMO (World Meteorological Organization). 2009. Manual on estimation of probable maximum precipitation (PMP). Geneva: WMO.

Zeimetz, F. 2017. "Development of a methodology for extreme flood estimations in alpine catchments for the verification of dam safety." $\mathrm{Ph} . \mathrm{D}$. thesis, Ecole polytechnique fédérale de Lausanne (EPFL)Faculté de l'environnement naturel, architectural et construit (ENAC)Laboratoire de constructions hydrauliques ( $\mathrm{LCH}$ ).

Zeimetz, F., J. García-Hernández, and A. Schleiss. 2015. "Extreme flood estimations on a small alpine catchment in Switzerland, the case study of Limmerboden." In Vol. 370 of Proc., Int. Association of Hydrological Sciences, 147-152. Gottingen: Copernicus GmbH.

Zeimetz, F., B. Schaefli, G. Artigue, J. G. Hernández, and A. J. Schleiss. 2017. "Relevance of the correlation between precipitation and the $0^{\circ} \mathrm{C}$ isothermal altitude for extreme flood estimation." J. Hydrol. 551 (Aug): 177-187. https://doi.org/10.1016/j.jhydrol.2017.05.022. 